\title{
Penentuan Dosis Paparan Radiasi Pesawat Sinar-X Pemeriksaan Thorax Berdasarkan Indeks Massa Tubuh (IMT)
}

\author{
${ }^{1}$ Aulia Nur Aisah, ${ }^{2}$ I Gusti Ngurah Sutapa, ${ }^{3}$ Nyoman Wendri \\ 1,2,3Prodi Studi Fisika, FMIPA, Universitas Udayana, Jimbaran, Bali, 80361 \\ Email Korespondensi: aulia.nuraisah@gmail.com¹, sutapafis97@unud.ac.id², \\ wendrinyoman@gmail.com
}

\begin{tabular}{|c|c|}
\hline ticle Info & \\
\hline $\begin{array}{l}\text { Bs } \\
\text { BMI, Exposure } \\
\text { Index } \quad \text { Expose, }\end{array}$ & $\begin{array}{l}\text { The determination of the Dose of Radiation Exposure Plane X-Ray } \\
\text { Examination of the Thorax Based on Body Mass Index (BMI). Theres been a } \\
\text { research that aims to determine the effect of exposure dose and the eksposi on } \\
\text { examination of the thorax against IMT adult patients. Data of a study that used } \\
\text { at the time of the observation is height and weight of the patient, faktor eksposi } \\
\text { which consists of the rated voltage ( } \mathrm{kV}) \text {, Current (mA) and time(s) as well as the } \\
\text { value of the FFD at the time of inspection. Data retrieval with the useof the type } \\
\text { of examination of the thorax with the type of irradiation of Posterior-Anterior } \\
\text { (PA). The age rangeof the patients who used the time of the study in accordance } \\
\text { with the rules of the department of HEALTH in the adult category, namely } 26- \\
45 \text { years. Testing on the test data using-F with a significance level of } 0.05 . \text { Based } \\
\text { on the results of the test data using test-F obtained a significance value of } 0.000 \\
\text { and the value of Fcount } 49,166 \text { with the value of the significance level of } 0.05 \\
\text { and the valueof Ftable of } 3.35 . \text { From these results meet thecriteria of testing in } \\
\text { statistics where HI is accepted and H0 is rejected, so it can be concluded that } \\
\text { there is influence on the value of the exposure dose and the value of the index } \\
\text { ekposi against Body Mass Index (BMI) where the value of the eksposi affect the } \\
\text { outcomeof the imageplane X-ray examination of the thorax. }\end{array}$ \\
\hline Informasi Artikel & \\
\hline $\begin{array}{l}\text { Kata kunci } \\
\text { Sinar-X, IMT, } \\
\text { Paparan, Nilai } \\
\text { Eksposi, Thorax }\end{array}$ & $\begin{array}{l}\text { Telah dilakukan penelitian yang bertujuan untuk mengetahui pengaruh dosis } \\
\text { paparan dan indeks eksposi pada pemeriksaan thorax terhadap IMT pasien } \\
\text { dewasa. Data peneltian yang digunakan pada saat pengamatan adalah berat dan } \\
\text { tinggi badan pasien, faktor eksposi yang terdiri dari tegangan }(\mathrm{kV}) \text {, Arus (mA) } \\
\text { dan waktu (s) serta nilai FFD pada saat pemeriksaan. Pengambilan data dengan } \\
\text { menggunakan jenis pemeriksaan thorax Posterior-Anterior (PA). Rentang usia } \\
\text { pasien yang digunakan saat penelitian sesuai dengan aturan DEPKES pada } \\
\text { kategori dewasa yaitu 26-45 tahun. Pengujian pada data menggunakan uji-F } \\
\text { dengan taraf signifikansi } 0,05 \text {. Berdasarkan hasil pengujian data menggunakan } \\
\text { uji-F diperoleh nilai signifikansi sebesar } 0,000 \text { dan nilai } F_{\text {hitung sebesar } 49,166} \\
\text { dengan nilai taraf signifikansi } 0,05 \text { dan nilai } F_{\text {tabel }} \text { sebesar } 3,35 \text {. Dari hasil } \\
\text { tersebut dinyatakan memenuhi kriteria pengujian dalam statistik dimana } \mathrm{H}_{1} \\
\text { diterima dan } \mathrm{H}_{0} \text { ditolak, sehingga dapat disimpulkan bahwa terdapat pengaruh } \\
\text { pada nilai dosis paparan dan nilai indeks ekposi terhadap Indeks Massa Tubuh } \\
\text { (IMT) dimana nilai indeks eksposi berpengaruh terhadap hasil citra pesawat } \\
\text { sinar-X pemeriksaan thorax. }\end{array}$ \\
\hline & \\
\hline
\end{tabular}

\section{PENDAHULUAN}

Pemanfaatan teknik nuklir dalam bidang kesehatan meliputi radioterapi dan tindakan radiodiagnostik di bagian radiologi (Yondri, 2008). Aplikasi teknik nuklir ini dapat pula memberikan ancaman bahaya radiasi yang merugikan pada manusia (Rahayuningsih, 2010). 
Salah satu contoh bahaya radiasi yang ditimbulkan yaitu munculnya efek radiasi pada kulit, antara lain : deskuamasi, epilasi, dan eritema (Alatas, 1998). Dampak terhadap efek jangka panjang (efek tertunda) yang ditimbulkan akibat paparan radiasi sinar-X, yaitu sebagai pencetus carsiogenik atau induksi kanker pada manusia (Hall dan Benner, 2008). Sinar-X ditemukan oleh Wilhelm Conrad Rontgen padatahun 1895. Informasi mengenai tubuh manusia dapat diketahui melalui gambar yang terbentuk pada permukaan film. Gambaran terbentuk akibat adanya perbedaan intensitas sinar-X yang mengenai permukaan film setelah sebagian sinar-X diserap oleh tubuh manusia (Yuliati, 2001).

Sinar-X yang berinteraksi dengan bahan atau tubuh manusia juga akan diteruskan dan dihamburkan. Banyaknya sinar-X yang diteruskan dan dihamburkan akan berpengaruh terhadap kualitas radiograf (gambar) yang dihasilkan, sedangkan yang diserap akan berpengaruh pada dosis radiasi yang diterima pasien. Faktor yang mempengaruhi kualitas film adalah faktor eksposi. Pengaturan faktor eksposi yang tepat akan menunjukkan perbedaan derajat kehitaman yang jelas antara organ yang memiliki kerapatan berbeda (Fahmi, 2008). Diagnosa penyakit pada pasien tentunya akan lebih akurat apabila diperoleh informasi yang cukup dari hasil gambaran (image) radiografi (Bayuadi, 2011). Dalam pemberian dosis pada pasien yang berlebihan akan membahayakan jaringan sehat yang lainnya sehingga dapat menimbulkan berbagai penyakit. Dosis serap radiasi yang akan diterima oleh pasien dapat diukur. Pemeriksaan menggunakan sinar-X dapat dilakukan pada semua kategori usia, berat dan tinggi badan. Hal tersebut yang menjadi latar belakang dilakukan penelitian mengenai pengaruh Indeks Massa Tubuh (IMT) pada pemeriksaan toraks terhadap dosis paparan radiasi pesawat sinar-X.

\section{METODE}

Penelitian dilakukan di Rumah Sakit Umum Daerah (RSUD) Sanjiwani Gianyar. Pengambilan data faktor eksposi sesuai dengan instruksi radiografer, kemudian pencatatan data pasien seperti umur, tinggi dan berat badan pasien. Pasien memasuki ruang radiologi dalam keadaan telah melepaskan benda-benda yang mengandung logam pada tubuh. Penyinaran dilakukan dengan posisi Posterior-Anterior (PA) dengan jarak FFD sebesar $150 \mathrm{~cm}$. Pasien dengan kategori normal dan gemuk menggunaan faktor eksposi yang sama yaitu $63 \mathrm{kV}$ dan 12,5 mAs. Pada pasien dengan kategori kurus menggunakan faktor eksposi sebesar $60 \mathrm{kV}$ dan 11,05 mAs. Setelah pengaturan ekspos selesai, akan dilakukan penyinaran pada pasien. Hasil dari penyinaran tersebut kemudian diolah menggunakan Computed Radiography (CR), kemudian dilakukan pencatatan nilai indeks eksposi yang tertera pada monitor.

Data yang telah diperoleh kemudian dikelompokkan berdasarkan kategori rentang um ur dewasa. Menurut Departemen Kesehatan RI tahun 2009 kategori dewasa dimulai pada umur 26 hingga 45 tahun. Besarnya nilai dosis paparan dapat dihitung secara matematis seperti pada persamaan dibawah ini.

Dimana $: D=$ Dosis paparan $(\mathrm{mR})$

$$
D=P \frac{V^{2} \times i \times t}{F F D^{2}}
$$

$P=$ Konstanta kesebandigan sebesar 15 (Meredith,1977)

$V=$ Tegangan pada tabung $(\mathrm{kV})$

$i=$ Arus tabung $(\mathrm{mA})$

$t=$ Waktu penyinaran (s)

FFD $=$ Jarak fokus ke film $(\mathrm{cm})$

\section{HASIL DAN PEMBAHASAN}

Pengambilan data pasien berupa umur, tinggi dan berat badan, faktor eksposi serta nilai indeks eksposi yang diperoleh pada saat penyinaran. Dosis paparan pada pasien pemeriksaan thorax dengan jenis penyinaran PA dihitung dengan menggunakan persamaan (1) yang kemudian 
dikonversikan kedalam satuan miligray (mGy). Hasil perhitungan nilai dosis dan nilai ratarata indeks eksposi yang diperoleh pada pemeriksaan thorax pasien dewasa dengan jenis penyinaran PA pada tiap kategori IMT ditampilkan pada tabel dibawah ini.

Tabel 1. Hasil konversi dosis paparan

\begin{tabular}{ccccc}
\hline Kategori & $\begin{array}{c}\text { Dosis Paparan } \\
(\mathbf{m R})\end{array}$ & $\begin{array}{c}\text { Dosis } \\
\text { Paparan }(\mathbf{R})\end{array}$ & $\begin{array}{c}\text { Dosis Serap } \\
(\mathbf{m G y})\end{array}$ & Indeks Eksposi \\
\hline Kurus & 26,52 & 0,02652 & 0,2326 & $1824,7 \pm 118,7$ \\
Normal & 33,075 & 0,033075 & 0,2901 & $1523,5 \pm 186,9$ \\
Gemuk & 33,075 & 0,033075 & 0,2901 & $1391,2 \pm 107,7$ \\
\hline
\end{tabular}

Data yang telah diperoleh kemudian diolah dan ditampilkan dalam bentuk grafik sebagai berikut.

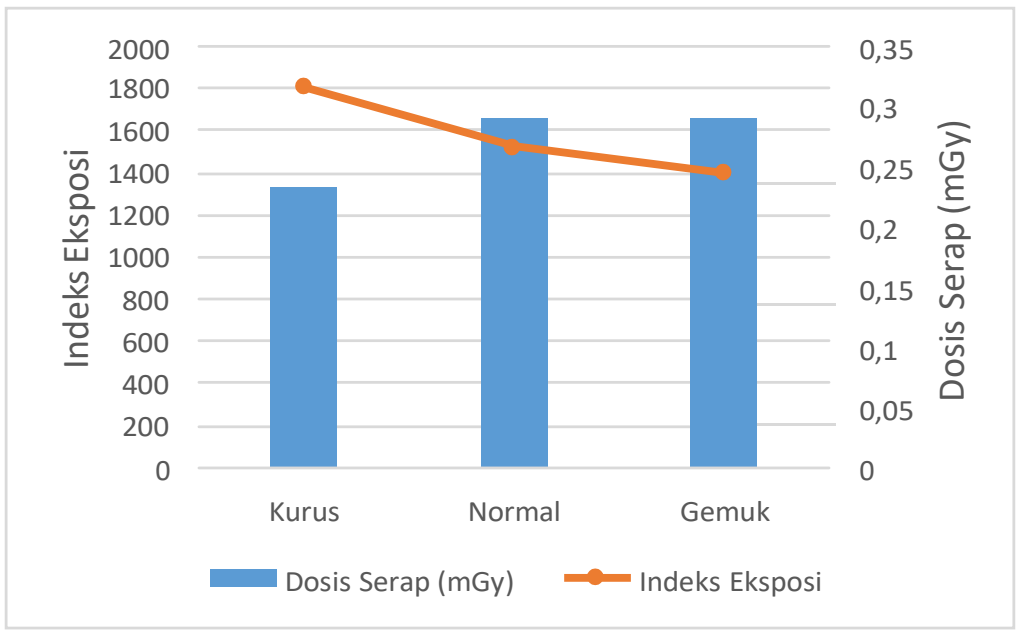

Gambar 1. Grafik antara dosis serap dan indeks eksposi terhadap IMT

Berdasarkan pada Gambar 1 dapat diketahui bahwa dosis serap pada pasien dengan kategori gemuk dan normal memperoleh nilai yang sama yaitu sebesar 0,2901 mGy. Nilai dosis serap yang diperoleh pada pasien kurus lebih kecil dibandingkan kategori lainnya yaitu sebesar 0,2326 mGy. Menurut Arfiansyah, 2018 menyatakan bahwa nilai dosis yang diterima pasien sangat berbeda dimana pasien gemuk mempunyai dosis yang lebih tinggi. Hal itu disebabkan oleh luas permukaan dan ketebalan objek. Untuk mendapatkan kualitas citra yang bagus maka pengaturan faktor eksposi harus lebih besar, sehingga mengakibatkan kenaikan nilai dosis. Sesuai dengan pernyataan tersebut dosis serap pada pasien dengan kategori normal dan gemuk lebih tinggi dibanding dengan kategori kurus.

Kesamaan nilai dosis serap pada pasien kategori normal dan gemuk disebabkan oleh faktor eksposi yang digunakan. Kesamaan nilai dosis tersebut tidak mempengaruhi perolehan nilai rata-rata indeks eksposi pada masing-masing kategori. Menurut Arfiansyah, 2018 menyatakan nilai arus tabung sinar-X berpengaruh terhadap nilai intensitas sinar. Intensitas ini pada hasil citra foto rontgen mempengaruhi nilai dari kehitaman pada film (densitas). Besarnya intesitas sinar-X yang diberikan sangat mempengaruhi kualitas pencitraan yang dihasilkan. Berikut merupakan hasil pencitraan pada tiap kategori.

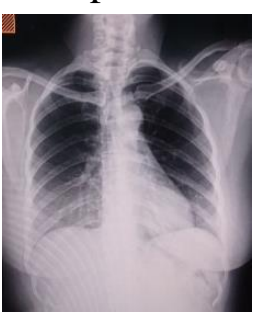

(a)

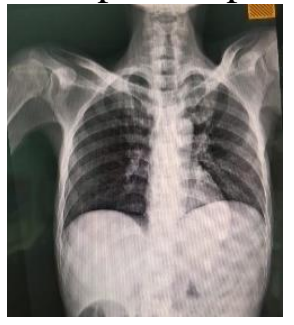

(b)

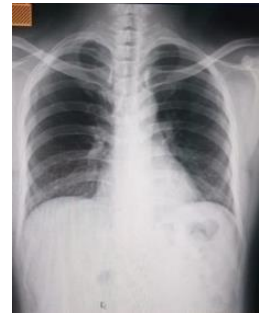

(c) 
Gambar 2 Hasil citra radiografi pemeriksaan thorax, (a) hasil citra yang baik (IMT Normal),(b) hasil citra over exspose (IMT Kurus), (c) hasil citra under expose (IMT Gemuk)

Gambar 2 merupakan hasil citra radiografi pemeriksaan thorax. Pada (a) terlihat hasil citra radiografi yang baik dengan nilai indeks eksposi sebesar 1553, dapat dilihat bahwa pada hasil citra ini tingkat kehitaman dan ketajaman citra yang dihasilkan baik digunakan untuk keakuratan diagnosa oleh dokter. Pada (b) dengan nilai IE yaitu sebesar 1754, terlihat hasil citra radiografi terjadi over exspose yang menyebabkan hasil citra menjadi lebih hitam sehingga menyebabkan penurunan terhadap kualitas citra yang dihasilkan. Pada (c) dengan nilai IE yaitu sebesar 1246 terjadi penurunan pada densitas (under expsose) yang dipengaruhi oleh radiasi hambur maka dari itu citra yang dihasilkan menjadi opaque atau buram.

Untuk mengetahui pengaruh dosis paparan dan indeks eksposi terhadap IMT dilakukan uji statistik. Uji statistik yang digunakan adalah uji-F dengan taraf signifikansi sebesar 0,05 . Uji asumsi klasik dilakukan sebelum pengujian data secara statistik. Uji multikolinieritas merupakan salah satu uji asumsi klasik yang bertujuan untuk menguji apakah pada model regresi ditemukan adanyakorelasi antar variabel independen. Jika terdapat atau terjadi korelasi, maka dinamakan terdapat problem multikolinieritas. Model regresi yang baik seharusnya tidak terjadi kerelasi di antara variabel independen (Nadiyah, 2012). Berikut hasil dari uji asumsi klasik multikolinieritas pada data peneltian.

Tabel 3. Hasiloutput SPSS uji mulikolinieritas

\section{Coefficientsa}

\begin{tabular}{lll|l}
\multicolumn{3}{c}{ Collinearity Statistics } \\
\multicolumn{3}{l}{ Model } & \multicolumn{2}{c}{ Tolerance } & \multicolumn{2}{c}{ VIF } \\
1 & Dosis Paparan &, 413 & 2,422 \\
\cline { 2 - 3 } & Indeks Eksposi &, 413 & 2,422 \\
\hline
\end{tabular}

a. Dependent Variable: IMT

Dari tabel Coefficients diatas menunjukkan bahwa tidak ada variabel independen yang memiliki nilai Tolerance kurang dari 0,100 yang berarti tidak ada korelasi antar variabel independen. Nilai VIF pada tabel Coefficients menunjukkan angka kurang dari 5. Dengan demikian dapat disimpulkan bahwa model pada penelitian ini memenuhi syarat untuk menjadi model regresi yang baik karena tidak terjadi korelasi antar variabel independen (nonmultikolinearitas)

Tabel 4 Hasiloutput SPSS uji simultan (uji-F)

\begin{tabular}{|c|c|c|c|c|c|c|}
\hline \multicolumn{7}{|c|}{ ANOVAa } \\
\hline Model & & Sum of Squares & df & Mean Square & $\mathrm{F}$ & Sig. \\
\hline \multirow[t]{3}{*}{1} & Regression & 15,691 & 2 & 7,846 & 49,166 &, $000^{\mathrm{b}}$ \\
\hline & Residual & 4,309 & 27 &, 160 & & \\
\hline & Total & 20,000 & 29 & & & \\
\hline
\end{tabular}

a. Dependent Variable: IMT

b. Predictors: (Constant), Indeks Eksposi, Dosis Paparan

Adapun hipotesis pada pengujian ini yaitu $\mathrm{H}_{0}$ : tidak ada pengaruh yang nyata (signifikan) antara dosis paparan dan indeks eksposi terhadap IMT, $\mathrm{H}_{1}$ : Ada pengaruh yang nyata (signifikan) antara dosis paparan dan indeks eksposi terhadap IMT dengan taraf signifikansi 0,05. Dari tabel 4 dapat dilihat bahwa hasil pengujian pada data mendapatkan nilai signifikansi sebesar 0,000 dengan $F_{\text {hitung }}$ sebesar 49,166. Berdasarkan hasil tersebut dapat dilihat bahwa nilai signifikansi yang diperoleh $<0,05$. Nilai $F_{\text {tabel }}$ yang diperoleh pada hasil pengujian yaitu sebesar 3,35 dimana nilai $F_{\text {hitung }}$ yang diperoleh lebih besar. Berdasarkan hal tersebut hipotesis 
nol $\left(\mathrm{H}_{0}\right)$ ditolak, $\mathrm{H}_{1}$ diterima yaitu adanya pengaruh dosis paparan dan nilai indeks eksposi terhadap IMT pada pasien dewasa.

\section{KESIMPULAN}

Berdasarkan penelitian yang telah dilaksanakan pada Rumah Sakit Sanjiwani Gianyar dapat disimpulkan bahwa IMT berpengaruh pada nilai dosis paparan, dimana semakin besar nilai IMT akan semakin besar nilai dosis paparan yang diterima oleh pasien. Pengaruh nilai indeks eksposi terhadap IMT yaitu semakin besar nilai IMT akan semakin kecil nilai indeks eksposi yang diperoleh. Hal tersebut akan berdampak pada hasil citra pemeriksaan thorax yaitu jika semakin kecil nilai indeks eksposi akan menurun kualitas hasil citra yang dihasilkan.

\section{SARAN}

Saran yang dapat disampaikan yaitu perlu dilakukan penelitian untuk pasien pemeriksaan thorax pada proyeksi AP dan lateral pasien dewasa berdasarkan IMT dengan faktor eksposi yang berbeda pada tiap kategori.

\section{UCAPAN TERIMA KASIH}

Ucapan terimakasih kepada pihak Rumah Sakit Sanjiwani, radiografer, staff pegawai yang terlibat dalam penelitian atas izin dan bantuan dalam pelaksanaan penelitian, serta dosen pembimbing yang telah memberikan masukan untuk kesempurnaan penulisan.

\section{DAFTAR PUSTAKA}

Alatas. (1998). Efek radiasi pada kulit.Bulletin ALARA,2(1): 27-31.

Arfiansyah, A. (2018). Penentuan Keluaran Radiasi Terhadap Pasien Berdasarkan Indeks Massa Tubuh Pada Pesawat X-Ray. Skripsi. Universitas Sumatra Utara, Medan.

Bayuadi, I. (2011). Optimasi Kualitas Citra dan Dosis Pada Pemeriksaan Thorak Menggunakan Computed Radiography. Skripsi. Universitas Indonesia, Jakarta.

Fahmi. (2008). Pengaruh Faktor Eksposi Pada Pemeriksaan Abdomen Terhadap Kualitas Radiografi Dan Paparan Radiasi Menggunakan Computed Radiography, Berkala Fisika, Vol. 11 No. 4 :109-118.

Hall, E. J. dan Brenner, D, J. (2008). Cancer Risk From Diagnostic Radiology.The British Journal of Radiology, 81:365-378.

Putra, IK., Ratnawati, GAA., Sutapa, GN. (2020). Monitoring of Patients Using Radiodiagnostic Dosage EI (Exposure Index) on CR (Computed Radiography). Internasional Research Journal of Enginering, IT and Scientific Research, Jilid 6 No.6 :45-49

Rahayuningsih, B., Murtini, M. S., Prasetya, N. K. (2010). Prediksi Dosis Paparan Radiasi dengan Menggunakan Metode Klastering pada Dosimeter Film. Prosiding Seminar Nasional Sains: 243-249.

Nadiyah, Diakses pada 30 September, 2021, Uji Asumsi Klasik: http://extraordinarynad.lecture.ub.ac.id/2012/12/uji-asumsi-klasik/

Yondri, 2008, “Analisis Perisai Radisai Sinar-X pada Ruang Penyinaran Radiodiagnostik RSUD Dr.Adnan W.D.Payakumbuh”, Tesis, Program Pasca Sarjana Universitas Andalas, Padang.

Yuliati, H. dan Akhadi, M. (2001). Prosiding Pertemuan dan Presentasi Dasar Ilmu dan Teknologi Nuklir P3TM. Optimisasi Proteksi dalam Pemeriksaan Foto Thorax . Jakarta: Puslitbang Keselamatan Radiasi dan Biomedika Nuklir, Batan. 
Tsalafoutas, I. A. (2008). Correlation Of Image Quality With Exposure Index and Procesing Protocol In A Computed Radiography System, Radiation Protection Dosimetry, Vol.130 :162171 